\title{
Acordo Brasil - Santa Sé - proteção dos bens culturais da Igreja: paixão e morte d'Ecce Homo
}

\author{
Holy See - Brasil agreement - protection of cultural heritage of the \\ Church: passion and death d'Ecce Homo
}

\section{Marcelino Donizeth de Melo Correia ${ }^{1}$}

Resumo: Com este texto, procura-se apontar a influência da Igreja sobre os referenciais simbólicos na cultura brasileira; demonstrar a importância da preservação dos bens eclesiásticos, por serem objetos simbólicos, com base no livro Imaginação Simbólica de Gilbert Durand; e, por fim, lançar uma proposta para a preservação do patrimônio eclesiástico.

Palavras-chave: Patrimônio eclesiástico, símbolo, preservação, conservação, Igreja.
Abstract: This text seeks to point out the influence of the Church on the symbolic references in Brazilian culture; to demonstrate the importance of the preservation of ecclesiastical goods, since they are symbolic objects, based on the book Symbolic Imagination of Gilbert Durand; and, finally, to launch a proposal for the preservation of the ecclesiastical patrimony.

Keywords: Ecclesiastical Patrimony. Symbol. Preservation. Conservation. Church.

\section{O Acordo Brasil - Santa Sé}

Depois da Primeira Missa no Brasil, há mais de 500 anos, em um evento histórico, foi firmado o Acordo abrangente entre a Santa Sé e o Brasil, em 13 de novembro de 2008, que tem como objetivo primeiro regulamentar as relações institucionais entre as duas unidades soberanas, com temas de interesse da sociedade brasileira.

1 Conservador/restaurador, trabalha há sete anos no Ateliê de ConservaçãoRestauração de Bens Culturais Móveis (ATECOR), órgão da Fundação Catarinense de Cultura (FCC); especialista em Linguagem Visual Contemporânea pela Universidade do Estado de Santa Catarina (UDESC); Bacharel em Pintura pela mesma Universidade. 
O Acordo Brasil - Santa Sé ${ }^{2}$ foi aprovado pelo Congresso Nacional, por meio do Decreto Legislativo $n^{\circ} 698 / 2009$, e promulgado pela Presidência da República, por meio do Decreto $\mathrm{n}^{\circ} 7.107$, de 11 de fevereiro de 2010, do. O Acordo também está publicado na Acta Apostolica Sedis ${ }^{3}$, no Vaticano. Ele tem uma abrangência de temas referentes às relações entre o Estado Brasileiro e a Igreja Católica, que também pode, não de forma explícita, envolver outras religiões, pois fala do exercício da liberdade religiosa.

Esse Acordo é composto por 20 artigos, contudo, vamos nos deter nos artigos $6^{\circ}$ e $7^{\circ}$, que dispõem sobre o Patrimônio Histórico e Cultural $^{4}$ pertencente à Igreja (que ora chamaremos de Patrimônio Eclesiástico $\left.^{5}\right)$.

No artigo $6^{\circ}$, o Brasil e a Igreja reconhecem o patrimônio eclesiástico (imóveis, móveis, alfaias, assim como os documentos custodiados nos seus arquivos e bibliotecas) como parte relevante do patrimônio cultural brasileiro e que, em colaboração mútua, há o compromisso de salvaguardá-lo.

O Brasil "reconhece a finalidade própria dos bens eclesiásticos", isto é, além de seu valor histórico cultural, é reconhecido o seu valor religioso. Em complemento, a Igreja deve comprometer-se a "facilitar o acesso a ele (bem eclesiástico) para todos os que o quei-

\footnotetext{
Acordo Brasil - Santa Sé. Brasília: Senado Federal, 2009.

VATICANO, Acta Apostolicae Sedis (A.A.S. 2010, n. 2): p. 118-129.
}

4 Patrimônio Cultural: É o conjunto de bens materiais e/ou imateriais, que contam a história de um povo através de seus costumes, comidas típicas, religiões, lendas, contos, danças, linguagem, superstições, rituais, festas. O Patrimônio Cultural de uma nação, de uma região ou de uma comunidade é composto de todas as expressões materiais e espirituais que lhe constituem, incluindo o meio ambiente. (CCSH/UFSM. O que é Patrimônio Cultural? Patrimônio Histórico? Patrimônio Ambiental ou Natural?)

5 Patrimônio eclesiástico é formado pelo conjunto de todos os bens de que a Igreja se utiliza para atingir seus fins próprios. No Código de Direito Canônico de 1983, o cânone 1254, $2 \S$, deixa claro que os bens eclesiásticos deverão ser empregados para "ordenar o culto divino, providenciar a honesta sustentação do clero e dos outros ministros, exercer obras do sagrado apostolado e de caridade, especialmente em favor dos necessitados". 
ram conhecer e estudar, salvaguardadas as suas finalidades religiosas e as exigências de sua proteção e da tutela dos arquivos " 6 .

Já no artigo $7^{\circ}$, há o reconhecimento, por parte do Brasil, da necessidade de proteção aos lugares de culto, da liturgia, dos símbolos, dos objetos culturais, contra toda e qualquer violação, uso indevido e ilegítimo e desrespeitos que possam sofrer. $\mathrm{O}$ referido artigo estabelece, também, o direito a todo católico de possuir seus símbolos religiosos. O Estado não pode demolir ou ocupar os imóveis, ou transportar os bens móveis, e não poderá ser destinado a outro fím, se não os seus fins próprios, conforme o cânone $1254, \S 2^{\circ}$.

Algo tão extraordinário quanto um Acordo entre o Brasil e a Santa Sé não poderia se furtar em conter a preocupação com assunto de tamanha importância, os bens históricos e culturais materiais ${ }^{8}$ e imateriais ${ }^{9}$ pertencentes à Igreja Católica, que fizeram, e ainda fazem, parte da evolução histórica, artística, social e religiosa da sociedade brasileira.

6 Acordo Brasil-Santa Sé, art. $6^{\circ}$.

7 Cânone 1254, § 2. Os fins próprios são principalmente os seguintes: ordenar o culto divino, providenciar a honesta sustentação do clero e dos outros ministros, exercer obras do sagrado apostolado e de caridade, especialmente em favor dos necessitados. (CÓDIGO DE DIREITO CANÔNICO. Editorial Apostolado da Oração, Braga, 2007).

8 Podemos dizer que patrimônio material são os aspectos mais concretos da vida humana, e que fornecem informações às pessoas. Segundo o IPHAN, é "composto por um conjunto de bens culturais classificados segundo sua natureza: arqueológico, paisagístico e etnográfico; histórico; belas artes; e das artes aplicadas. Podem ser imóveis, sítios arqueológicos e paisagísticos e bens individuais; ou móveis, como coleções arqueológicas, acervos museológicos, documentais, bibliográficos, arquivísticos, videográficos, fotográficos e cinematográficos.” (IPHAN- http://portal.iphan.gov.br/pagina/detalhes/276).

9 Segundo o IPHAN: "Os bens culturais de natureza imaterial dizem respeito àquelas práticas e domínios da vida social que se manifestam em saberes, ofícios e modos de fazer; celebrações; formas de expressão cênicas, plásticas, musicais ou lúdicas; e nos lugares, como mercados, feiras e santuários que abrigam práticas culturais coletivas. A Constituição Federal de 1988, em seus artigos 215 e 216, ampliou a noção de patrimônio cultural ao reconhecer a existência de bens culturais de natureza material e imaterial. (IPHAN- http://portal.iphan.gov.br/ bcrE/pages/conPatrimonioE.jsf). 
No que se refere ao patrimônio eclesiástico, tanto as normas e leis do Estado quanto as normas canônicas e documentos eclesiásticos não se contrapõem uns aos outros. O mesmo acontece nesse Acordo, que ratifica a colaboração mútua que o Estado e a Igreja sempre encontraram no Brasil para a proteção desse patrimônio.

A Igreja Católica Apostólica Romana sempre esteve presente no Brasil desde o descobrimento. A partir da colonização, com a chegada dos jesuítas em 1549, a Igreja enraizou-se na sociedade brasileira. Dessa forma, a Igreja veio permeando e moldando a formação brasileira, tanto religiosa, como administrativa, social, estética, artística e cultural. A maioria das grandes cidades surgiu de povoados, em grande parte, sendo a igreja o epicentro do local.

T. S. Eliot, em seu livro Notas para uma Definição Cultural ${ }^{10}$, afirma que "nenhuma cultura pode surgir ou desenvolver-se, salvo em relação a uma religião". Se ele estiver correto, não restam dúvidas de que a partir do momento em que foi fincada a primeira cruz no solo brasileiro, com a chegada de Cabral, a Igreja Católica está na base da formação da cultura brasileira e foi determinante na formação social, na construção dos referenciais simbólicos e na criação do patrimônio cultural material e imaterial.

Sob a guarda da Igreja, encontra-se um conjunto de bens móveis e imóveis de incomensurável valor, o qual sobrepõe os valores materiais, que testemunham a história das pessoas, das comunidades, das cidades, do país, enraizando-se na memória individual e coletiva do lugar.

Tanto a Constituição Brasileira, a Lei de tombamento e as cartas patrimoniais quanto o Código de Direito Canônico, as Cartas Episcopais e os documentos da Comissão Pontificia para a Conservação do Patrimônio Histórico e Artístico da Igreja prevêem a preservação desse patrimônio. Contudo, há algo errado, alguma coisa não está dando certo, pois estamos perdendo muitos bens patrimoniais, por infindáveis motivos, mas acreditamos que os principais sejam a falta de conhecimento, esclarecimento e orientação.

10 T. S. ELIOT, Notas para uma Definição de Cultura. Editora Perspectiva, São Paulo, 1988, p. 40. 


\section{Simbolismo}

Precisamos repensar, discutir e agir quanto à forma adequada de conservação do patrimônio eclesiástico, tendo, como corolário, a sua preservação para futuras gerações. Vale lembrar que a perda de algum bem pode significar não apenas a perda do valor material, inclui-se também a perda dos valores simbólicos, ressaltando que esses não são possíveis de dimensionar ou julgar, não são perceptíveis e não são passíveis de compreensão racional, ou através das realidades inteligíveis.

Vejamos como isto ocorre:

Há alguns anos, esteve no Ateliê de Conservação-Restauração de Bens Culturais Móveis (ATECOR) uma imagem devocional de São João Batista pertencente à paróquia de São João Batista da cidade de Imaruí. Pelo fato de estar em precário estado de conservação, precisou sofrer procedimentos de restauração. Contam as restauradoras da época que essa imagem ficou vários meses sendo restaurada no Ateliê, e que, durante esse processo, devotos de São João Batista, às vezes, vinham da cidade de Imaruí visitar a imagem. Nesses encontros, os devotos oravam perante a imagem, e muitos deles sentiam tanta emoção que até choravam ${ }^{11}$.

Um pequeno livro de Gilbert Durand ${ }^{12}$, chamado Imaginação Simbólica, discorre sobre a importância dos símbolos nas sociedades. Para ele, "a consciência dispõe de duas maneiras para representar o mundo" "13; a primeira: a direta, que se mostra através das sensações e percepções, e a segunda: a indireta, aquela realidade que não conseguimos apreender imediatamente, que se apresenta através de um símbolo, onde o significante e o significado estão contidos no mesmo ob-

11 São memórias contadas por restauradores de mais tempo na profissão, que trabalharam no Ateliê de Conservação-Restauração de Bens Culturais Móveis. Hoje a maioria está aposentada da Instituição.

12 Gilbert Durand (1921, 2012), antropólogo e sociólogo francês, Agregado em Filosofia e Doutor em Letras, foi Professor Titular Universitário (Sociologia e Antropologia Cultural) da Universidade de Grenoble II, hoje Universidade Pierre Mendès France (França).

13 G. DURAND, A imaginação simbólica. Lisboa, Edições 70, 2000, p. 7. 
jeto. Esse símbolo se oferece sempre palpável, sempre visível, conhecível - nos referimos ao significante -; mesmo assim, nunca mostra de forma concreta o in-figurável, o transcendente, ele só se refere a um sentido sempre abstrato, "não é de modo algum apresentável" significado.

O símbolo gera sentidos que não estão presentes em nossas percepções, contudo, a capacidade humana torna possível produzi-los cheios de significados, que são guardados em nossa memória mais profunda e que alicerçam a nossa visão de mundo. O símbolo torna compreensível o inacessível. Sempre é uma fonte infindável de sabedoria e conhecimento.

[...] tal modo de conhecimento nunca adequado, nunca «objectivo», dado que nunca atinge um objecto e se pretende sempre essencial porque se basta a si próprio e que traz em si mesmo, de modo escandaloso, a mensagem imanente de uma transcendência, nunca explícita, mas sempre ambígua e geralmente redundante... ${ }^{15}$

Redundante porque se repete, tanto no significado, como no significante. Todas as vezes que um homem de fé faz o sinal da cruz, através dessa ação simbólica, ele faz a evocação ao Divino. Na imanência contida no seu gesto repetido - o rito -, o homem, através da fé, busca incansavelmente o Divino transcendente.

$\mathrm{Na}$ história que contamos sobre a imagem restaurada no ATECOR, ao fazerem as orações perante a imagem, os devotos têm acesso direto ao sagrado não sacramental, pois não estão subordinados à ação eclesiástica do sacramento; o que ocorre é algo espontâneo que os leva a uma realidade impossível de se chegar através da razão e inexplicável através da dialética. É a epifania do inexplicável.

Mesmo ali, não sendo um local sagrado no sentido religioso, o fato vivido foi, sem dúvida, uma experiência religiosa perante aquela imagem sagrada, onde os devotos tiveram uma súbita revelação da presença do Divino - experiência única a cada nova manifestação epifânica.

14 G. DURAND, A imaginação simbólica, p. 10.

15 G. DURAND, A imaginação simbólica, p. 16. 


\section{Perda dos Valores e Referenciais Simbólicos}

Em seu livro Imaginação Simbólica, Durand ${ }^{16}$ diz que, apesar de vivermos em uma sociedade onde a maior parte das nossas comunicações e conhecimentos são passados e repassados através de imagens, essa sociedade é extremamente iconoclasta.

Para Durand ${ }^{17}$, esse iconoclasmo foi agravado "por evaporação de sentidos". Para ele, há "três estados" primordiais para a ocorrência do fenômeno. Primeiro: as igrejas impuseram o dogma e clericalismo em oposição às epifanias transcendentais; segundo: o pragmatismo que impõe o pensamento direto, em contraposição ao pensamento indireto; e terceiro: a ciência passa a considerar a imaginação "mestre do erro e da falsidade", ficando determinado que seja ela, a ciência, somente ela, a única fonte do conhecimento válido, buscando-se, assim, razões para tudo em explicações semiológicas e positivistas ${ }^{18}$.

Esses "três estados" podem ser três etapas de perturbação da consciência e obscurecimento do pensamento, que gradativamente causa a "extinção simbólica". O que equivale a dizer, a "extinção progressiva do poder humano de relação com a transcendência, do poder de mediação natural do símbolo" "19.

Ao observarmos nossa sociedade, percebemos que estamos perdendo alguns objetos e ações que são mediações simbólicas entre o consciente e o inconsciente, que podem ajudar na estruturação da vida e da visão de mundo do ser humano. A cada dia, podemos intuir que nossos valores e percepções simbólicas são substituídos por outros valores e outras percepções, às vezes distorcidos, quando não repassados por interesses obscuros, deixando a sociedade doente.

16 G. DURAND, A imaginação simbólica, p. 19.

17 G. DURAND, A imaginação simbólica, p. 20.

18 "Positivismo: A filosofia de Auguste Comte, que sustenta que a única forma de conhecimento, ou a mais elevada, é a descrição de fenômenos sensoriais. Comte afirmava que existiam três estágios na crença humana: o teológico, o metafísico e, por fim, o positivo, assim chamado por se limitar ao que é positivamente dado, evitando toda especulação." (S. BLACBURN, Dicionário Oxford de Filosofia. Rio de Janeiro: Jorge Zahar Ed, 1997, p. 304).

19 G. DURAND, A imaginação simbólica, p. 35. 


\begin{abstract}
Marinaide Ramos Moura, estudando Ernest Cassirer $^{20}$, diz o seguinte:
\end{abstract}

[...] somos nós que plasmamos o mundo com nossa atividade simbólica, somos nós que criamos e fazemos mundos em nossas experiências. Logo a criação do mito, da religião, da linguagem, da arte, da história são todos símbolos, que nos realizam como seres humanos e somos nós que engendramos esses mundos, criando significados baseados em nossas experiências, dentro de uma estrutura social e cultural, é por isso que Cassirer diz que, deveríamos definir o homem como animal symbolicum e não como rationale $e^{21}$.

Portanto, se todo ser humano é um ser simbólico, podemos concluir que, se nossas relações simbólicas com o mundo não estão funcionando direito, ficamos doentes. "É certo que, no limite, como bem viram Cassirer e Jung, a doença é a perda da função simbólica"22. Em consequência, a sociedade adoece. Isso pode ser constatado lendo e vendo as notícias de jornais.

Se há perturbações nas nossas representações e percepções simbólicas, nosso pensamento é doentio, pois perdemos "o "poder de analogia» e no qual os símbolos se desfazem, se esvaziam de sentido ${ }^{, 23}$.

Acreditamos que, se resgatarmos os símbolos e ações simbólicas perdidas, seria possível termos mais fontes para que o consciente acesse os conteúdos do inconsciente e, assim, facilitarmos para o ser a obtenção do conhecimento de si mesmo, trazendo um sentido à vida. Pois, como afirma Durand, "Qualquer manifestação da imagem re-

20 "Cassirer, historiador da filosofia e antropólogo, teve seu reconhecimento após a $2^{a}$ guerra mundial, a partir de 1945 , pelo seu denso estudo da filosofia das formas simbólicas, impregnado de um racionalismo no qual estende a problemática kantiana às formas simbólicas como o campo das produções constitutivas da cultura.” (M. R. MOURA, O Simbólico em Cassirer. Revista Ideação, Feira de Santana, n. 5, p.75-85, jan./jun. 2000, p. 76).

21 M. R. MOURA, O Simbólico em Cassirer. Revista Ideação, Feira de Santana, n. 5, p. 75-85, jan./jun. 2000, p. 76.

22 G. DURAND, A imaginação simbólica, p. 102.

23 G. DURAND, A imaginação simbólica, p. 55. 
presenta uma espécie de intermediário entre um inconsciente não manifesto e uma tomada de consciência ativa "24.

Dessa forma, a preservação das nossas representações simbólicas, as que ainda restam, contribuirá para que saibamos do nosso lugar no mundo, pois, como nos diz Durand ${ }^{25}$, a ação do símbolo é restauradora no ser humano, tem uma função reguladora, considerando que, para ele, a função da imaginação é trazer ao ser um equilíbrio biológico, psíquico e sociológico. Ele define imaginário como: "O conjunto das relações de imagens que constituem o capital pensado do homosapiens",26, que o símbolo é "o dado primordial da consciência humana"27 e que todo processo de simbolização está na imagem.

Assim, o que serve como base antropológica para a construção de significados históricos são o símbolo, o mito e as ações simbólicas.

\section{Ecce Homo}
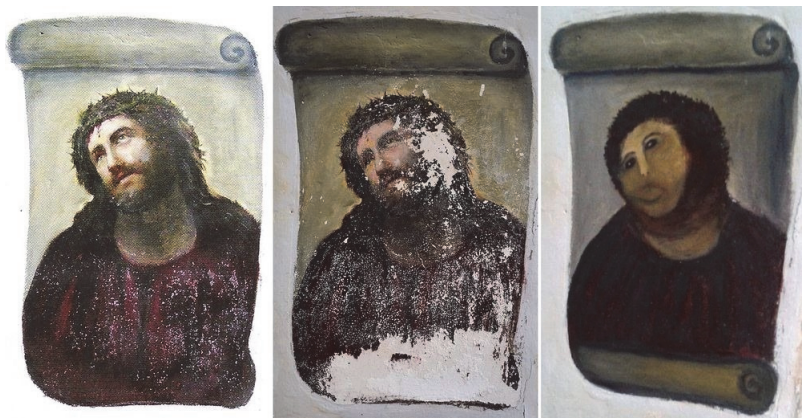

Figura 1

Ecce Homo, obra de Elias Garcia Martinez, que sofreu intervenção por Cecília Gimenez, Espanha.

24 G. DURAND apud E. T. SILVA, e E. S. L. GOMES, A Hermenêutica Simbólica e o Fenômeno Religioso.

25 G. DURAND, A imaginação simbólica, p. 103.

26 G. DURAND, A imaginação simbólica, p. 14.

27 DURAND, apud L. P. MINUZZI, Mia Couto e Sua Avenida de Sonhos: Um estudo de Antes de nascer o mundo e seus símbolos. Revista da Graduação. Vol. 5, n. 1, 2012, 22, p. 14. 
Considerando correto o que afirma Gilbert Durand, é necessário e importante que se preservem os nossos bens culturais, lembrando que patrimônio cultural abrange aqueles itens carregados de valores simbólicos, que fazem parte de nossa memória individual e coletiva, e são nossos referenciais, podendo ser sociais, culturais, históricos e sacros. Às vezes, esses valores encontram-se conjugados em um mesmo objeto.

Tratando-se do patrimônio eclesiástico, além dos valores citados, possui ainda aquele valor que remete ao sobrenatural, ao sagrado, ao místico, ao transcendente, que traz ao ser experiências religiosas. Em muitos desses objetos, por serem símbolos, está intrínseco um sentido secreto, que os torna "epifania de um mistério"28.

Sempre nos deparamos com notícias de sumiço de imagens e objetos sacros de nossas igrejas, por furto e roubos, mas temos também a perda de bens por falta de conservação e por ações de restauro inadequadas realizadas por pessoas que não têm os conhecimentos técnicos para tal. Um exemplo clássico é o afresco "Ecce Homo", de Elias Garcia Martinez, que pertence à igreja do Santuário de Misericórdia de Borja, na Espanha, em que uma senhora, chamada Cecília Gimenez, ousou "restaurar", causando uma desfiguração irreparável na obra.

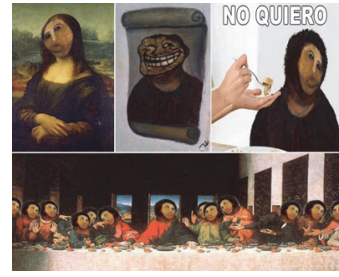

Figura 2

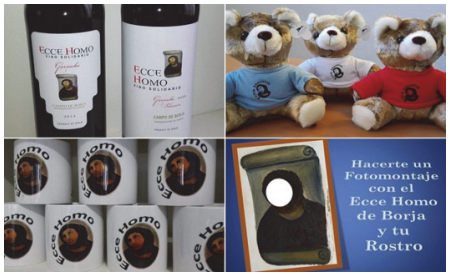

Figura 3

Ecce Homo ganhou fama com muitos memes pela internet e já foi transformado em marca de produtos elaborados na região.

Nesse episódio ocorrido na Espanha e em muitos recorrentes no Brasil, faltou, e continua faltando, às pessoas responsáveis pelo bem cultural capacidade de avaliar a situação com bom senso e clareza e

28 G. DURAND, A imaginação simbólica, p. 12. 
perceber que aquele bem é muito valioso para deixar alguém, sem a mínima referência e expertise em restauração, fazer qualquer reparo nas imagens. Nessas ocasiões, é necessário buscar informações e orientações para tomar a melhor decisão sobre o que pode ou não ser feito numa situação similar. E, sobretudo, faltou, por parte dos responsáveis, conhecimento das leis e normas, tanto eclesiásticas como as leis do Estado $^{29}$. Resumindo, faltaram conhecimento, esclarecimento e orientação.

Vale ressaltar que, quando perdemos um objeto do patrimônio cultural, perdemos, também, uma parte de nosso referencial simbólico, cultural e social e parte de nossa construção histórica. Dessa forma, desaparece a ação restauradora desse símbolo e nossa identidade vai ao esquecimento. Se esse bem for eclesiástico, o prejuízo é muito maior, pois uma fonte que nos conecta ao Divino também é perdida.

Portanto, precisamos evitar casos como a obra Ecce Homo, que era um patrimônio em conexão com o Divino. Em uma ação insensata por parte das pessoas responsáveis em salvaguardá-la e de alguém sem os conhecimentos técnicos necessários para executar a "restauração", um símbolo, que era respeitado e sagrado, foi transformado em algo ridículo e alvo de anedotas e chacotas.

Triste fim d'Ecce Homo!

\section{Uma proposta à preservação do patrimônio eclesiástico}

No Concílio Vaticano II, foi criada a Constituição Conciliar Sobre a Sagrada Liturgia - Sacrosanctum Concilium. Em seu artigo 44, a Constituição sugere a formação nas dioceses de comissões de liturgia, música e arte sacra:

Convém que a autoridade eclesiástica territorial competente, a que se refere o art. $22 \S 2$, crie uma Comissão litúrgica, que deve servir-se da ajuda de especialistas em liturgia, música, arte sacra e pastoral. A Comissão deverá contar, se possível, com o auxílio dum Instituto de Liturgia Pastoral, de cujos membros não se excluirão leigos particularmente competentes, se for ne-

29 Quando nos referimos a "Estado", tratamos dos poderes federais, estaduais e municipais. 
cessário. Será atribuição da dita Comissão dirigir, guiada pela autoridade eclesiástica territorial, a pastoral litúrgica no território da sua competência, promover os estudos e as experiências necessárias sempre que se trate de adaptações a propor à Santa $\mathrm{Sé}^{30}$. (grifo nosso)

Hoje algumas dioceses formaram Comissões Diocesanas para os Bens Culturais da Igreja e do Espaço Sagrado, que se responsabilizam pelo patrimônio eclesiástico. Quanto aos membros que as constituem, o ideal seria que houvesse entre eles, no mínimo, uma pessoa especializada em preservação e conservação de patrimônio cultural, se possível, uma equipe. O custo-benefício com a participação de membros com tal expertise é altamente favorável, visto que ações inadequadas poderiam ser evitadas, ao mesmo tempo em que haveria um incremento de ações efetivas e adequadas para a salvaguarda do patrimônio. Entre suas funções, estaria a de levar tanto os conhecimentos e informações - tão necessários aos párocos, padres, administradores e fiéis - quanto as formas adequadas para a preservação do patrimônio eclesiástico. Esse membro seria, também, um orientador.

Assim, além da preservação dos bens eclesiásticos, seriam evitadas também ações ilegais, que podem trazer constrangimentos legais às paróquias.

A Igreja Católica enquanto instituição possui a consciência do alto valor de seu patrimônio, contudo, é imprescindível que todo o clero esteja sensibilizado e consciente do grande tesouro que está sob sua responsabilidade e da necessidade de preservação de todo patrimônio eclesiástico, caso contrário, não adiantará muito qualquer ação no sentido de proteger esse patrimônio.

\section{BIBLIOGRAFIA}

ACORDO BRASIL - SANTA SÉ. Brasília: Senado Federal, 2009. Disponível em: <http://www2.senado.leg.br/bdsf/handle/ id/243036>. Acesso em: 5 maio 2017.

30 VAticAno, Constituição Conciliar, Sacrosanctum Concilium, Sobre A Sagrada Liturgia, art. 44. 
BLACBURN, S. Dicionário Oxford de Filosofia. Rio de Janeiro: Jorge Zahar, 1997.

BRASIL. Constituição da República Federativa do Brasil - 1988. Brasília: Coordenação de Edições Técnicas, 2016. Disponível em: $<$ https://www2.senado.leg.br/bdsf/bitstream/handle/id/518231/CF 88_Livro_EC91_2016.pdf >. Acesso em: 23 jan. 2018.

CÓDIGO DE DIREITO CANÔNICO. Braga: Editorial Apostolado da Oração, 2007. DURAND, G. A imaginação simbólica. Lisboa: Edições 70, 2000.

ELIOT, T. S. Notas para uma definição de cultura. São Paulo: Perspectiva, 1988. Disponível em: <https://issuu.com/ marcostoledo4/docs/eliot_t.s._notas_para_a_defini_>. Acesso em: 11 jun. 2017.

IPHAN (1). Patrimônio Cultural [s.d]. Disponível em: $<$ http://portal.iphan.gov.br/pagina/detalhes/218>. Acesso em: 21 jan. 2018.

(2). Patrimônio material. [s.d]. Disponível em: $<$ http://portal.iphan.gov.br/pagina/detalhes/276>. Acesso em: 15 jan. 2018.

, (3). O que é patrimônio imaterial? [s.d]. Disponível em: $<$ http://portal.iphan.gov.br/bcrE/pages/conPatrimonioE.jsf>. Acesso em: 15 jan. 2018.

MAGNUS MUNDI. Ecce Homo, a restauração fracassada que salvou uma cidade. [s.d]. Disponível em: <http://www. magnusmundi.com/ecce-homo-restauracao-fracassada-que-salvou-umacidade/>. Acesso em: 24 nov. 2017.

MINUZZI, L. P. Mia Couto e sua avenida de sonhos: um estudo de Antes de Nascer o Mundo e seus símbolos. Revista da Graduação Publicações de TCC, v. 5, n. 1, p. 1-74, 2012. Disponível em: $<$ http://revistaseletronicas.pucrs.br/ojs/index.php/ graduacao/article/view/11422/7774>. Acesso em: 22 jan 2018.

MOURA, M. R. O simbólico em Cassirer. Revista Ideação, Feira de Santana, n. 5, p. 75-85, jan./jun. 2000. Disponível em: <http://gepai. 
yolasite.com/resources/O\%20SIMB $\% \mathrm{C} 3 \% 93 \mathrm{LICO} \% 20 \mathrm{EM} \% 20$ CASSIRER.pdf>. Acesso em: 22 maio 2017.

SILVA, E. T.; GOMES, E. S. L. A hermenêutica simbólica e o fenômeno religioso. Anais - A Condição Humana: olhares da espiritualidade, educação, saúde e tecnologia - 1 a 5/out/2012. Instituto de Formação Humana Recife/PE Disponível em: $<$ https://docs.wixstatic.com/ugd/89838f_166170e8cf394532b4c 388c4df4761aa.pdf $>$. Acesso em: 22 jan. 2018.

VATICANO. Acta Apostolicae Sedis - A.A.S. 02 [2010]. Città del Vaticano: Libreria Editrice Vaticana, 2010.

. Constituição Conciliar - Sacrosanctum Concilium sobre a Sagrada Liturgia. Roma, 1963. Disponível em: <http:// www.vatican.va/archive/hist_councils/ii_vatican_council/docum ents/vat-ii_const_19631204_sacrosanctum-concilium po.html>. Acesso em: 22 jan. 2018. 